\title{
Outcomes following selective fetoscopic laser ablation for twin-to-twin transfusion syndrome: a single-centre experience
}

\author{
Michelle $\underline{L o h}^{1}$, MBBS, Anju Bhatia ${ }^{2}$, MBBS, MRCoG, Kai Lit ${\underline{T a n^{2}}}^{2}$, MBBS, MRCOG, Edwin $\underline{\text { Thia }}^{2}$, MBBS, MRCOG,
} George Seow Heong $\underline{\mathrm{YeO}}^{2}$, MBBS, FRCOG

INTRODUCTION Fetoscopic laser photocoagulation (FLP), a treatment option for twin-to-twin transfusion syndrome (TTTS) in monochorionic twin pregnancies, is currently the treatment of choice at our centre. We previously reported on our experience of FLP from June 2011 to March 2014. This paper audits our fetal surgery performance since then. METHODS 15 consecutive patients who underwent FLP for Stage II-III TTTS before 26 weeks of gestation from June 2011 to January 2017 were retrospectively reviewed, consisting of five cases from our initial experience and ten subsequent cases. Perioperative, perinatal and neonatal outcomes were analysed.

RESULTS Of 15 pregnancies, 10 (66.7\%) and 5 (33.3\%) were for Stage II and III TTTS respectively, with FLP performed at an earlier Quintero stage in the later cohort. Overall mean gestational ages at presentation, laser and delivery were comparable between the cohorts at 19.7 (15.4-24.3) weeks, 20.3 (16.3-25.0) weeks and 31.2 (27.6-37.0) weeks, respectively. 2 (13.3\%) cases had intra-amniotic bleeding and 1 (6.7\%) had iatrogenic septostomy. 1 (6.7\%) case had persistent TTTS requiring repeat FLP, and another (6.7\%) had preterm premature rupture of membranes at seven weeks post procedure. The overall perinatal survival rate was $21(75.0 \%)$ out of 28 infants. One mother underwent termination of pregnancy for social reasons at 1.4 weeks post procedure. Double survival occurred in 8 (57.1\%) out of 14 pregnancies, while $13(92.9 \%)$ had at least one survivor.

CONCLUSION FLP requires a highly specialised team and tertiary neonatal facility. Continual training improves maternal and perinatal outcomes, ensuring comparable standards with international centres.

Keywords: fetoscopic laser photocoagulation, monochorionic, twin-to-twin transfusion syndrome

\section{INTRODUCTION}

Monochorionic (MC) twins account for $20 \%$ of spontaneous twin pregnancies. ${ }^{(1)}$ Sharing a placental mass and fetoplacental circulation, MC twins are interdependent, predisposing them to specific serious complications based on intertwin discordance, including fetal size, amniotic fluid volume, fetoplacental haemodynamics and structural defects. Management of these specific complications requires great expertise, as the risks of neurological damage and death, respectively, are 15\% and $26 \%$ in the surviving twin after a single fetal death. Twinto-twin transfusion syndrome (TTTS) is the most common serious complication, occurring in approximately $15 \%$ of MC twin pregnancies. Untreated TTTS carries a perinatal loss of $70 \%-90 \%$. $^{(2)}$ It usually presents after 16 weeks of gestation and rarely after 26 weeks.

TTTS results from chronic imbalanced, unidirectional blood flow from artery to vein through placental arteriovenous anastomoses between the two fetal circulations sharing similar placental masses. ${ }^{(3,4)}$ The donor hence manifests signs of hypovolaemia and growth discordance, with oliguria, oligohydramnios and abnormal umbilical artery (UA) Doppler studies. The recipient twin, conversely, shows signs of being overloaded: polyhydramnios, cardiomegaly with abnormal venous Doppler studies (reverse flow in the ductus venosus [DV]) or pulsatile flow in the umbilical vein and hydrops.

Fetoscopic laser photocoagulation (FLP) as a treatment for TTTS was first reported in the early 1990s. ${ }^{(5)}$ Increased experience has led to refinement of the technique with good outcomes, ${ }^{(5,6)}$ and it is now superior to serial amnioreduction in TTTS diagnosed at less than 26 weeks of gestation. ${ }^{(7,8)}$ TTTS was first introduced at KK Women's and Children's Hospital (KKH), Singapore, in June 2011. FLP has since been our choice of treatment for Stage II-III TTTS in MC twin pregnancies presenting between 16 and 26 weeks of gestation. We previously reported our experience with five cases that underwent FLP at our centre from June 2011 to March 2014. ${ }^{(9)}$ This study reviews our overall perioperative, perinatal and neonatal outcomes, and more importantly, audits our fetal surgery performance since then.

\section{METHODS}

We conducted a retrospective single-centre review of all MC diamniotic twin pregnancies that were (a) complicated by TTTS of at least Stage II; (b) presented before 26 weeks of gestation; and (c) underwent FLP in our unit from June 2011 to January

${ }^{1}$ Department of Obstetrics and Gynaecology, 2Department of Maternal Fetal Medicine, KK Women's and Children's Hospital, Singapore 
2017. A total of 15 cases were reviewed, five cases from June 2011 to March $2014^{(9)}$ and ten cases subsequently. TTTS was diagnosed using the basic ultrasonography (US) criteria and staged according to the Quintero criteria, ${ }^{(10)}$ as follows - Stage I: ultrasonography finding of fluid discrepancy between the two fetuses (polyhydramnios in the recipient [i.e. deepest vertical pool (DVP) $>8 \mathrm{~cm}$ at $\leq 20$ weeks' gestation or $>10 \mathrm{~cm}$ at $>20$ weeks gestation] and oligohydramnios in the donor [DVP $\leq 2 \mathrm{~cm}]$ ); Stage II: absence of visualisation of the donor's fetal bladder; Stage III: abnormal Doppler findings; Stage IV: the presence of hydrops; and Stage $V$ : the fetal demise of one or both twins.

Patients were informed of their diagnosis and management options, consisting of FLP, amnioreduction or cord coagulation. Procedure information, particularly FLP and its associated risks including fetal loss, preterm membrane rupture, miscarriage and neurological deficit in the surviving twin(s), was conveyed and an informed choice was made by the patient. Sonographic data on placental localisation and extent, umbilical cord insertion sites, amniotic fluid volume, umbilical vessel, DV and middle cerebral artery (MCA) blood flow as well as cardiac function was collected. The vascular equator, where vessels from either twin anastomose, giving rise to arteriovenous, arterio-arterial (AA) and venovenous anastomoses, was mapped using colour flow Doppler studies. In particular, AA anastomoses were identified.

Informed consent was taken and prophylactic antibiotics administered 30 minutes before the procedure. All procedures were performed by a team of trained operators in the Antenatal Diagnostic Centre at our institution. Instruments included the 2-mm fetoscope (HOPKINS $®$ II Straight Forward Telescope $0^{\circ}$ 26008AA; Karl Storz, Tuttlingen, Germany) that was used previously, and the current 3.3-mm fetoscope (Miniature Straight Forward Telescope $0^{\circ} 11506$ AA; Karl Storz, Tuttlingen, Germany), diode laser with a 600- $\mu \mathrm{m}$ laser fibre (Dornier Medilas D MultiBeam; Dornier MedTech, Wessling, Germany), vascular access trocar and cannula (Terumo Radifocus 11F; Terumo Corporation, Tokyo, Japan).

Under US guidance, an avascular area was located perpendicular to the stuck twin and the site of fetoscopic entry was planned based on the placental location and placental cord insertions of both twins. The patient was positioned accordingly in a supine or lateral decubitus position depending on the placental location. Local anaesthetic (subcutaneous infiltration of $1 \%$ lignocaine) was given in all cases at the planned entry site on the maternal abdomen. This was followed by a 3-mm skin incision. The trocar and cannula were inserted into the amniotic cavity of the recipient twin using the Seldinger method perpendicular to the vascular equator. In cases of an anterior or fundal placenta, a $30^{\circ}$ scope was used to overcome poor visualisation of vessels. FLP was performed using the Solomon technique:(11) after anastomotic vessels along the vascular equator were selectively identified and coagulated using the laser at $30 \mathrm{~W}$, surface coagulation of the placenta between the ablated anastomotic sites was carried out, creating a physical separation of the donor's and the recipient's vascular territories on the placenta surface and ablating the superficial AA anastomoses. An anastomosis was identified if the vessel originated from one cord and ended in a cotyledon from which the other emerging vessel ran towards the cord of the other twin. Vessels were not coagulated if the emerging vessel led back to the same twin. At the end of the procedure, amnioreduction was performed in the recipient sac to attain normal liquor volume (DVP $<8 \mathrm{~cm}$ ). Sonographic assessments of fetal viability and cervical length were also done at the end of the procedure.

After the procedure, patients were admitted for one day for observation and given antibiotics and progesterone. Analgesia and tocolytics were given on demand. Doppler studies (UA, DV and MCA) of both twins as well as fetal viability were routinely performed the next day before discharge.

Cases were closely followed up in the Fetal Medicine Clinic at least once or twice a week initially and later fortnightly for evidence of resolution, persistence or recurrence of TTTS as well as other complications. Persistent TTTS was defined as the persistence of polyhydramnios-oligohydramnios sequence in at least one week following FLP, although no general consensus exists on its precise definition. Parameters measured each visit included DVP, visualisation of fetal bladder, standard deviation score of abdominal circumference and Doppler studies.

Patient demographics, operative details, perioperative and postoperative complications, as well as pregnancy and perinatal outcomes were prospectively collected and retrospectively reviewed. Overall survival rate was calculated using the number of surviving fetuses divided by the total number of fetuses. The double fetal survival rate was the proportion of pregnancies in which both fetuses survived. The at-least-one-twin survival rate was the proportion of pregnancies in which one or both fetuses survived. Obstetric, fetal and neonatal data was obtained from medical records in all cases.

Neonatal death was defined as the number of deaths in infants who were born alive at $\geq 24$ weeks of gestation but who died within 28 days. Weight discordance was assessed in surviving pairs of twins and was calculated in the following manner: ([birth weight of the larger twin - birth weight of the smaller twin]/birth weight of the larger twin) $\times 100 \%$. Significant weight discordance was defined as $>25 \%$.

\section{RESULTS}

A total of 28 cases of MC twin pregnancies with Stage II-IV TTTS presented to our unit from June 2011 to January 2017. Of these, three cases went to an overseas institute for further management and another three went to another centre for a second opinion. A further seven cases were unsuitable candidates for FLP, as three cases presented after 26 weeks of gestation and underwent serial amnioreduction, and four cases underwent cord coagulation. In the cord coagulation cases, FLP was technically not possible in two patients due to anatomical or positional causes, including unfavourable placenta positions (anterior/fundal) with close cord insertions and a stuck twin overlying the site of the vascular equator. In the other two cases, it was the patient's choice: in one, the donor twin had severe intrauterine growth restriction and in the other, the recipient twin had severe fetal hydrops. The remaining 15 cases underwent FLP, five cases from June 
Table I. Antenatal characteristics of 15 cases of monochorionic twin pregnancies that underwent fetoscopic laser photocoagulation in our centre.

\begin{tabular}{|c|c|c|c|}
\hline \multirow[t]{2}{*}{ Parameter } & \multicolumn{3}{|c|}{ No. (\%) } \\
\hline & Overall $(n=15)$ & Cases 1-5 $(n=5)$ & Cases 6-15 $(n=10)$ \\
\hline Maternal age* (yr) & $31.1(22-41)$ & $34.0(28-41)$ & $29.7(22-37)$ \\
\hline \multicolumn{4}{|l|}{ Ethnicity } \\
\hline Chinese & $10(66.7)$ & $4(80.0)$ & $6(60.0)$ \\
\hline Malay & $2(13.3)$ & $0(0)$ & $2(20.0)$ \\
\hline Indian & $0(0)$ & $0(0)$ & $0(0)$ \\
\hline Others & $3(20.0)$ & $1(20.0)$ & $2(20.0)$ \\
\hline \multicolumn{4}{|l|}{ Parity } \\
\hline Nulliparous & $10(66.7)$ & $3(60.0)$ & $7(70.0)$ \\
\hline Multiparous (1-3) & $5(33.3)$ & $2(40.0)$ & $3(30.0)$ \\
\hline \multicolumn{4}{|l|}{ TTTS stage } \\
\hline II & $10(66.7)$ & $2(40.0)$ & $8(80.0)$ \\
\hline III & $5(33.3)$ & $3(60.0)$ & $2(20.0)$ \\
\hline \multicolumn{4}{|l|}{ Gestational age (wk) } \\
\hline At diagnosis* & $19.7(15.4-24.3)$ & $19.8(16.7-23.0)$ & $19.7(15.4-24.3)$ \\
\hline At procedure* & $20.3(16.3-25.0)$ & $20.6(19.3-23.1)$ & $20.2(16.3-25.0)$ \\
\hline Intergrowth discordance* (\%) & $37.9(3.9-60.0)$ & $48.8(39.0-60.0)$ & $31.1(3.9-59.0)$ \\
\hline \multicolumn{4}{|l|}{ Placenta } \\
\hline Anterior & $6(40.0)$ & $2(40.0)$ & $4(40.0)$ \\
\hline Posterior & $9(60.0)$ & $3(60.0)$ & $6(60.0)$ \\
\hline
\end{tabular}

*Data presented as mean (range).

2011 to March $2014^{(9)}$ and ten cases from November 2014 to January 2017.

Overall, $66.7 \%$ of the cases had Stage II and $33.3 \%$ had Stage III TTTS. Table I summarises the antenatal characteristics of all the cases. A comparison of the two cohorts (Cases 1-5 vs. Cases 6-15) showed that the earlier group was older. Mean gestational ages at diagnosis and procedure were comparable across both groups. FLP was, however, performed at an earlier Quintero stage (i.e. less severe) in the later cohort, with $80.0 \%$ and $20.0 \%$ of cases being Stage II and III, respectively, compared to $40.0 \%$ and $60.0 \%$ in the earlier cohort. The later cohort also had a smaller weight discrepancy of $31.1 \%$ compared to $48.8 \%$ in the earlier cohort. Overall, all but two cases in the later cohort had an intergrowth discordance of $>20 \%$ at diagnosis. $40.0 \%$ of all the cases had an anterior placenta, which was comparable between the two cohorts. Amnioreduction was performed in all cases post procedure, with a mean volume of 1,597 $(600-3,000) \mathrm{mL}$.

Two cases (one case each from the earlier and later cohorts) had intra-amniotic bleeding during the procedure, which resolved spontaneously. Needle insertion in the uterine wall resulted in haematoma formation and bleeding in the first case, while the second case bled from accidental vessel puncture on the placental surface. latrogenic septostomy, inadvertent perforation of the twins' dividing membranes, occurred in Case 14. There were no cases of intraprocedure fluid leak.

Complications were reported in three cases during post procedure follow-up. Case 4 had persistent TTTS despite FLP at 20.3 weeks and amnioreduction at 23.1 weeks (Day 19 post FLP), requiring a repeat FLP at 24.3 weeks (Day 28 post initial FLP).
Case 9 had preterm premature rupture of membranes (PPROM) at 24.6 weeks (Day 48 post FLP). Case 10 was noted to have a shortened cervical length of $0.2 \mathrm{~cm}$ with cervical dilatation of $0.6 \mathrm{~cm}$, necessitating placement of an emergency cerclage at 21.7 weeks (Day 2 post FLP). There were no cases of placental abruption or twin anaemia polycythemia sequence (TAPS), or any maternal complications such as amniotic fluid embolism, disseminated intravascular coagulation, stay in the intensive care unit and Mirror syndrome - a rare and potentially life-threatening obstetric complication characterised by the development of maternal oedema and preeclampsia in association with fetal hydrops. Table II summarises the complications seen in our patients.

Since July 2015, our unit has routinely performed magnetic resonance (MR) imaging of the fetal brain for all cases at four weeks post procedure. During the study period, normal results were seen in all six cases that underwent fetal MR imaging of the brain, with all fetuses showing no evidence of neurological damage at birth.

One recipient and two cases of donor demise were recorded at one day post procedure. Both donors were noted before FLP to be severely growth restricted, with one of them exhibiting absent end-diastolic flow. The recipient was noted to be severely growth restricted prior to FLP, with absent reversed end-diastolic flow and cardiomegaly with poor cardiac contractions. These pregnancies were followed up closely in our MC twin clinic.

Analysis of the Doppler images (Fig. 1) revealed that the majority of the recipients showed an increase in their middle cerebral artery pulsatility index (MCAPI) and middle cerebral artery peak systolic velocity (MCAPSV) after the procedure. 
Table II. Post-FLP complications in 15 cases of monochorionic twin pregnancies that underwent FLP in our centre.

\begin{tabular}{|c|c|c|c|}
\hline \multirow[t]{2}{*}{ Parameter } & \multicolumn{3}{|c|}{ No. } \\
\hline & Overall $(n=15)$ & Cases $1-5(n=5)$ & Cases 6-15 $(n=10)$ \\
\hline \multicolumn{4}{|l|}{ Intraoperative } \\
\hline Bleeding & 2 & 1 (Case 2) & 1 (Case 6) \\
\hline Septostomy & 1 & 0 & 1 (Case 14) \\
\hline Fluid leak & 0 & 0 & 0 \\
\hline \multicolumn{4}{|l|}{ Maternal } \\
\hline AFE/DIVC/ICU stay & 0 & 0 & 0 \\
\hline \multicolumn{4}{|l|}{ Pregnancy } \\
\hline PPROM & 1 & 0 & 1 (Case 9) \\
\hline Cervical cerclage & 1 & 0 & 1 (Case 10) \\
\hline Recurrence of TTTS & 1 & 1 (Case 4) & 0 \\
\hline Placental abruption/TAPS/Mirror syndrome & 0 & 0 & 0 \\
\hline
\end{tabular}

AFE: amniotic fluid embolism; DIVC: disseminated intravascular coagulation; FLP: fetoscopic laser photocoagulation; ICU: intensive care unit; PPROM: preterm premature rupture of membranes; TAPS: twin anaemia polycythemia sequence; TTTS: twin-to-twin transfusion syndrome
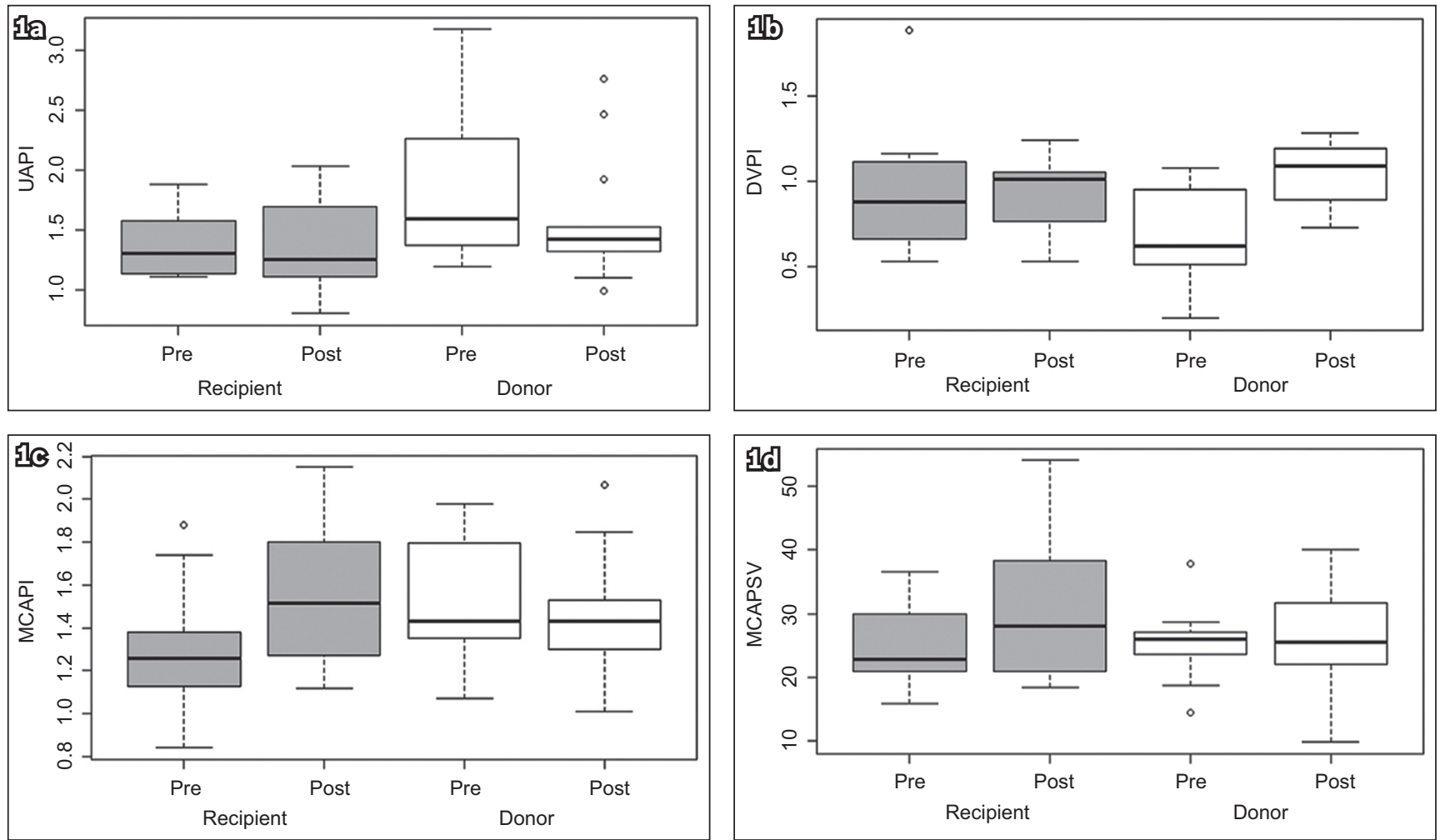

Fig. 1 Doppler studies show pre- and postprocedure (a) umbilical artery pulsatility index (UAPI); (b) ductus venosus pulsatility index (DVPI); (c) middle cerebral artery pulsatility index (MCAPI) and (d) middle cerebral artery peak systolic velocity (MCAPSV) in both the recipient and donor.

Umbilical artery pulsatility index (UAPI) increased in half of the recipients. Most donors showed a reduction in UAPI, MCAPI and MCAPSV. The DV pulsatility index (DVPI) was noted to increase in both the donors and recipients post FLP.

One woman in the later cohort subsequently underwent a mid-trimester termination of pregnancy at 24 weeks of gestation (at postprocedure 1.4 weeks) due to social reasons. Perinatal survival rates are thus reported based on 14 pregnancies and 28 fetuses (Table III \& Fig. 2). The overall, double and single fetal survival rates were $75.0 \%, 57.1 \%$ and $35.7 \%$, respectively, across the 14 cases. $92.9 \%$ of the cases had at least one survivor.
Perinatal outcomes are described in Table IV, based on 14 pregnancies and 21 live births. The majority of the babies were delivered after 28.0-31.9 weeks of gestation due to worsening fetal Doppler findings and intrauterine growth restriction; $14.3 \%$ were delivered at less than 28 weeks of gestation. 10 (71.4\%) out of the 14 pregnancies were delivered via Caesarean section. Mean gestational age at delivery was 31.2 (27.6-37.0) weeks, with a procedure-to-delivery interval of 11.1 (5.7-18.6) weeks.

When compared with the earlier cohort, the overall, double and at-least-one fetal survival rates were higher in the later cohort, with no dual demise (Table III and Fig. 2). There were no significant differences between gestational age at procedure 
Table III. Perinatal survival rates in 14 cases of monochorionic twin pregnancies that underwent FLP in our centre.

\begin{tabular}{|c|c|c|c|}
\hline \multirow[t]{2}{*}{ Parameter } & \multicolumn{3}{|c|}{ No./total (\%) } \\
\hline & $\begin{array}{l}\text { Overall } \\
\text { (14 P, } 28 \text { F) }\end{array}$ & $\begin{array}{l}\text { Cases 1-5 } \\
(5 \mathrm{P}, 10 \mathrm{~F})\end{array}$ & $\begin{array}{l}\text { Cases 6-15 } \\
(9 \mathrm{P}, 18 \mathrm{~F})\end{array}$ \\
\hline Overall survival at birth* & $21 / 28(75.0)$ & $6 / 10(60.0)$ & $15 / 18(83.3)$ \\
\hline Double fetal survival $^{\dagger}$ & $8 / 14(57.1)$ & $2 / 5(40.0)$ & $6 / 9(66.7)$ \\
\hline Single fetal survival ${ }^{+}$ & $5 / 14(35.7)$ & $2 / 5(40.0)$ & $3 / 9(33.3)$ \\
\hline $\begin{array}{l}\text { At-least-one-twin } \\
\text { survival }^{+}\end{array}$ & $13 / 14(92.9)$ & $4 / 5(80.0)$ & $9 / 9(100.0)$ \\
\hline Dual demise $^{\dagger}$ & $1 / 14(7.1)$ & $1 / 5(20.0)$ & $0(0)$ \\
\hline Donor demise & 4/14 (28.6) & $2 / 5(40.0)$ & $2 / 9(22.2)$ \\
\hline Recipient demise & $3 / 14(21.4)$ & $2 / 5(40.0)$ & $1 / 9(11.1)$ \\
\hline
\end{tabular}

1 pregnancy was terminated due to social reasons. *Per fetus. †Per pregnancy.

F: fetuses; FLP: fetoscopic laser photocoagulation; P: pregnancies

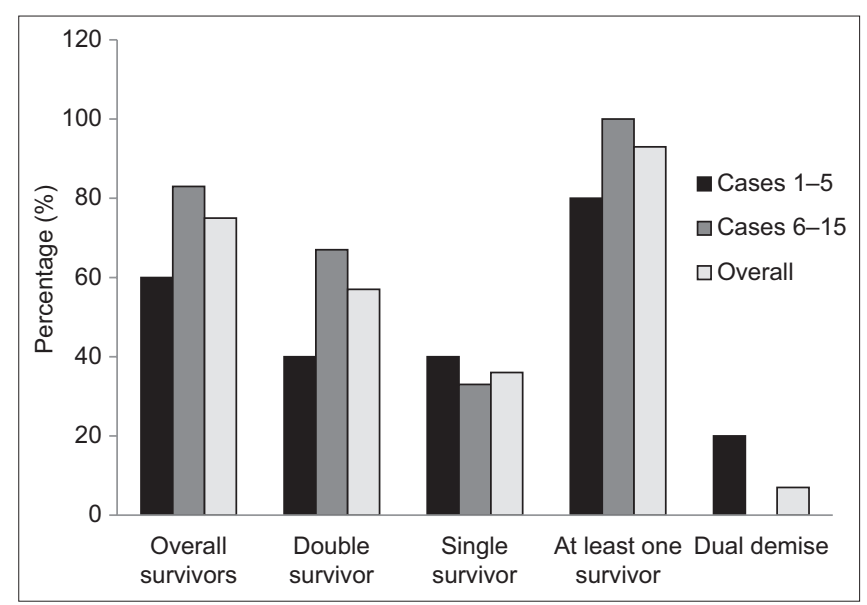

Fig. 2 Bar chart shows a comparison of perinatal outcomes between the earlier cohort (Cases 1-5) and the later cohort (Cases 6-15) of patients who underwent fetoscopic laser photocoagulation.

Table IV. Overall perinatal outcomes in 14 cases of monochorionic twin pregnancies that underwent FLP in our centre.

\begin{tabular}{|c|c|c|c|}
\hline \multirow[t]{2}{*}{ Parameter } & \multicolumn{3}{|c|}{ No./total (\%) } \\
\hline & Overall (14 P, 21 F) & Cases 1-5 (5 P, 6 F) & Cases 6-15 (9 P, 15 F) \\
\hline Gestational age at delivery* (wk) & $31.2(27.6-37.0)$ & $30.2(27.6-34.0)$ & $31.8(27.7-37.0)$ \\
\hline$<28$ & $2(14.3)$ & $1(20.0)$ & $1(11.1)$ \\
\hline $28-31.9$ & $7(50.0)$ & $3(60.0)$ & $4(44.4)$ \\
\hline $32-36.9$ & $4(28.6)$ & $1(20.0)$ & $3(33.3)$ \\
\hline$>37$ & $1(7.1)$ & $0(0)$ & $1(11.1)$ \\
\hline Procedure-to-delivery interval* (wk) & $11.1(5.7-18.6)$ & $9.6(6.6-14.6)$ & $11.9(5.7-18.6)$ \\
\hline \multicolumn{4}{|l|}{ Mode of delivery } \\
\hline Vaginal & $4(28.6)$ & $2(40.0)$ & $2(22.2)$ \\
\hline LSCS & $10(71.4)$ & $3(60.0)$ & $7(77.8)$ \\
\hline \multicolumn{4}{|l|}{ Birth weight* (g) } \\
\hline Donor & $1,212.3(773-1,900)$ & $917.7(773-1,200)$ & $1,338.6(880-1,900)$ \\
\hline Recipient & $1,466.7(898-2,000)$ & $1,576.3(1,224-2,000)$ & $1,425.6(898-2,000)$ \\
\hline \multicolumn{4}{|l|}{ Apgar score* } \\
\hline At $1 \mathrm{~min}$ & 8.1 & 8.2 & 8.1 \\
\hline At 5 min & 8.7 & 8.7 & 8.7 \\
\hline Total hospital stay* (day) & 64.7 & 97 & 55 \\
\hline Infant survival at discharge & $20(95.2)$ & $5(83.3)$ & $15(100.0)$ \\
\hline
\end{tabular}

*Data presented as mean (range). F: fetuses; FLP: fetoscopic laser photocoagulation; LSCS: lower-segment Caesarean section; P: pregnancies

$(p=0.76)$, gestational age at delivery $(p=0.33)$ and procedure-todelivery interval $(p=0.31)$ between the earlier and later cohorts.

Comparatively, the birth weight of the donor twin was greater in the later cohort $(1,338.6 \mathrm{~g}$ vs. $917.7 \mathrm{~g})$. Although the recipient's birth weight was lower in the later cohort, the birth weight difference between the donor and recipient was significantly smaller than that of the earlier cohort $(6.1 \%$ vs. $41.8 \%$ ). The total length of the neonatal hospital stay was shorter in the later cohort compared to the earlier cohort (55 days vs. 97 days)

There were 21 survivors at birth, of whom $18(85.7 \%)$ required a newborn intensive care unit stay. Among the 3 (14.3\%) infants who did not, one was delivered at 36.7 weeks (single survivor) and two at 37 weeks (double survivor). Neonatal death occurred in 1 $(4.8 \%)$ live-born infant, an ex-donor twin from the earlier cohort on
Day 17 of life, due to multiple complications of severe prematurity and sepsis. Table $\mathrm{V}$ summarises the neonatal outcomes.

\section{DISCUSSION}

With better knowledge on TTTS over the past three decades, various interventions have been developed to improve pregnancy outcomes and reduce neonatal morbidity and mortality. These include serial amnioreduction, intertwin septostomy, cord coagulation and FLP. In particular, with the evolution of laser techniques from non-selective to selective sequential as well as the Solomon technique, perinatal survival has significantly increased. ${ }^{(12)}$

Since the first paper on FLP, ${ }^{(13)}$ different surgical techniques have been developed for carrying it out. Non-selective laser coagulation of placental vessels was initially described, in which any vessel 
Table V. Overall neonatal outcomes for all survivors at birth $(n=21)$.

\begin{tabular}{|llll|}
\hline \multirow{2}{*}{ Parameter } & \multicolumn{3}{c|}{ No. (\%) } \\
\cline { 2 - 4 } & $\begin{array}{l}\text { Overall } \\
(\mathbf{n = 2 1 )}\end{array}$ & $\begin{array}{l}\text { Cases 1-5 } \\
\text { (n=6) }\end{array}$ & $\begin{array}{l}\text { Cases 6-15 } \\
(\mathbf{n}=\mathbf{1 5})\end{array}$ \\
\hline Need for intubation & $7(33.3)$ & $2(33.3)$ & $5(33.3)$ \\
\hline Need for inotropes & $2(9.5)$ & $2(33.3)$ & $0(0)$ \\
\hline RDS & $14(66.7)$ & $3(50.0)$ & $11(73.3)$ \\
\hline NNJ & $13(61.9)$ & $4(66.7)$ & $9(60.0)$ \\
\hline IVH & $2(9.5)$ & $2(33.3)$ & $0(0)$ \\
\hline NEC & $1(4.8)$ & $0(0)$ & $1(6.7)^{*}$ \\
\hline 2D echo & & & \\
\hline VSD & $2(9.5)$ & $1(16.7)$ & $1(6.7)$ \\
\hline Pulmonary valve stenosis & $2(9.5)$ & $1(16.7)$ & $1(6.7)$ \\
\hline Pulmonary valve atresia & $1(4.8)$ & $1(16.7)$ & $0(0)$ \\
\hline Sepsis & $5(23.8)$ & $3(50.0)$ & $2(13.3)$ \\
\hline
\end{tabular}

* Baby had congenital cytomegalovirus. 2D echo: two-dimensional echocardiography; IVH: intraventricular haemorrhage; NEC: necrotising enterocolitis; NNJ: neonatal jaundice; RDS: respiratory distress syndrome; VSD: ventricular septal defect

crossing the intertwin membranes (i.e. membranous equator) was coagulated, ${ }^{(5)}$ followed by selective laser coagulation of placental vessels (SLCPV), in which anastomoses crossing between the twins (i.e. vascular equator) were coagulated. ${ }^{(14)}$ Most recently, the Solomon technique, first described by the Leiden group in the Netherlands, (15) involves SLCPV with subsequent surface coagulation of the placenta between the ablated anastomotic sites to create a physical separation of the donor's and recipient's vascular territories on the placental surface. It has been reported to reduce residual anastomoses, potentially reducing complications such as recurrent TTTS or TAPS with no increase in adverse outcomes. ${ }^{(11)}$

Several studies have compared the success rates of FLP with other treatments of TTTS. The Eurofetus study demonstrated that pregnancies complicated by Stage II or III TTTS treated with FLP had a higher likelihood of survival of at least one twin to 28 days and 6 months of age compared to serial amnioreduction. ${ }^{(7)}$ Similarly, a meta-analysis of ten articles, eight of which classified TTTS via Quintero staging, found that fetuses with Stage II-III TTTS undergoing laser ablation were twice as likely to survive and had an $80 \%$ reduction in neurologic morbidity compared with fetuses undergoing serial amnioreduction. ${ }^{(8)}$ Selective fetocide with cord coagulation remains an option, with $80 \%-90 \%$ survival of the remaining twin and no neurological abnormalities at birth reported. ${ }^{(16)}$ With the introduction of FLP, however, cord coagulation remains possibly a last resort for preterminal TTTS. ${ }^{(9)}$

In pregnancies where TTTS was diagnosed after 26 weeks, management options included delivery or amniodrainage. Most published series of TTTS cases treated with laser surgeries are limited to gestation ages under 26 weeks; ${ }^{(7,17)}$ FLP is usually not advocated as the treatment of choice in late presentations of TTTS, possibly due to its higher rates of complications such as PPROM compared to amniodrainage. ${ }^{(18)}$

Performing FLP in MC twins with an anterior placenta is known to be technically more challenging than in those with a posterior placenta due to a higher risk of injury and bleeding. For these patients, our approach included a detailed pre-fetoscopy US mapping of fetal positions, placental locations and cord insertions. A curved fetoscope coupled with a more lateral approach for fetoscope insertion was undertaken to clearly visualise the placental anastomosis.

The severity of TTTS at diagnosis and gestation age at delivery remain the main factors in determining the perinatal outcomes of such pregnancies. ${ }^{(19)}$ Early diagnosis and timely intervention are thus imperative to achieve the best outcomes. In our study, the overall mean gestational age at diagnosis and procedure was 19.7 weeks and 20.3 weeks respectively, comparable to the mean gestational age at procedure in the international data, which was $20.9 \pm 1.9$ weeks. ${ }^{(12)}$ When the earlier and later cohorts were compared, $80.0 \%$ of patients who underwent FLP in the later cohort had Stage II TTTS compared to $40 \%$ in the earlier cohort. This can be attributed to the earlier detection of TTTS through greater awareness and screening, together with the fact that our centre is the largest tertiary maternal unit in the country.

In our study, most donors showed a reduction in UAPI, MCAPI and MCAPSV, while the majority of the recipients showed increased resistance in UA blood flow (UAPI) and an increase in MCAPI and MCAPSV after the procedure. Our results are similar to those of various papers ${ }^{(20-22)}$ in which fetal vasoconstriction maintained blood pressure and minimised changes in cerebral blood flow secondary to the drop in systemic blood flow in recipients after FLP, leading to an increase in MCAPI.

DVPI has been noted to increase in donors following FLP, a transient rise associated with benign hydropic findings due to transient relative hypervolaemia, congestive heart failure and hypertension. ${ }^{(21,22)}$ In the present study, there was an increase in DVPI in the majority of the recipients. This was surprising, as a reduction would be expected following FLP. ${ }^{(23)}$ Flow pulsatility in the DV is usually a reflection of pressure changes in the inferior vena cava and right atrium. ${ }^{(24)}$ Pressure is usually elevated together with other signs of right heart overload in the recipients prior to FLP. Our findings may be explained by the limited data available (six out of 14 cases).

The most common serious complication following FLP is PPROM, which has an incidence of as high as $27 \%^{(25)}$ and carries significant neonatal morbidity and mortality due to complications from preterm labour, prematurity and chorioamnionitis. ${ }^{(26)}$ In our series, 1 (6.7\%) out of 15 cases had PPROM on postprocedure Day 48, at 24.6 weeks of gestation. Other complications reported in the literature include TAPS, (27) recurrence of TTTS in $29.6 \%$ of pregnancies post $\mathrm{FLP}^{(28)}$ and adverse long-term neurodevelopmental outcomes in $6 \%-18 \%$ of survivors. ${ }^{(29)}$ In our series, Case 4 had persistent TTTS requiring repeat FLP at 24.3 weeks (Day 28 post initial FLP) and Case 10 required an emergency cerclage at 21.7 weeks (Day 2 post procedure).

Following FLP, MC twins with TTTS are at an increased risk of neurodevelopmental impairment, with a $6.1 \%$ and $11.1 \%$ rate of neurologic morbidity at birth and at 6-48 months of age, respectively. ${ }^{(30,31)}$ The risks, however, do not differ significantly from the baseline risks of $\mathrm{MC}$ twin pregnancies without 
TTTS matched for gestational age at delivery, suggesting that neurological damage may be secondary to complications of prematurity rather than a direct result of TTTS or FLP. ${ }^{(32)}$ Prenatal MR imaging has been an established method in the diagnosis of brain damage after FLP. ${ }^{(17)}$ In our study, there was good correlation between the results of fetal MR imaging of the brain and neurological outcome at birth for all our patients, with no intrauterine death or evidence of neurological damage reported in the surviving twin after delivery. This can likely be attributed to the success of our laser procedure in achieving division of all significant vascular communications between the twins.

The mean gestational age at delivery was 31.2 weeks in our study and was comparable between both cohorts (Cases 1-5: 30.2 weeks, Cases 6-15: 31.8 weeks). This is significantly earlier than the $32.4 \pm 1.3$ weeks reported in the literature ${ }^{(12)}$ and was likely due to our more cautious approach to management of these complicated twin pregnancies with a lower threshold for delivery. Six women were delivered due to worsening Doppler findings and severe intrauterine growth restriction, and five due to preterm labour. Despite the earlier mean gestational age at delivery of the later cohort, infants in this group had a shorter hospital stay (55 days vs. 97 days) compared to those in the earlier cohort, reflecting the improved knowledge and experience of our neonatal unit, the largest one in Singapore, in managing preterm babies. Although neonatal morbidities were comparable in both the earlier and later cohorts, there was a higher rate of respiratory distress syndrome in the later cohort $(73.3 \%$ vs. $50.0 \%)$. This may be attributed to the larger number of emergency Caesarean sections that were performed for these pregnancies for causes unrelated to TTTS, leading to inadequate time for steroid injection.

The double, single and at-least-one fetal survival rates in our study were $57.1 \%, 35.7 \%$ and $92.9 \%$ respectively. In a systematic review of 34 studies with 3,868 MC twin pregnancies published over the last 25 years, ${ }^{(12)}$ the mean perinatal survival of both twins, one twin and at least one twin was 52\% $\pm 14.8 \%, 29 \% \pm 10.5 \%$ and $81 \% \pm 8.3 \%$, respectively. The overall survival rate of fetuses was $69.1 \%$, which is comparable to the rate of $75 \%$ in our study.

Comparing the two cohorts, better perinatal outcomes (overall, double and at least one survivor) were observed in the later cohort compared to the earlier cohort, with $100 \%$ survival of at least one fetus in the later cohort. Although gestational age at diagnosis and procedure were similar in both cohorts, gestational age at delivery was more advanced in the later cohort (31.8 weeks vs. 30.2 weeks), translating to a longer procedure-to-delivery interval (11.9 weeks vs. 9.6 weeks). Possible reasons for this were a more experienced team and better facilities and equipment. In July 2015, from Case 5 onwards, our institution opened the Fetal Surgery Suite, a place dedicated to fetal procedures, and we started using the 3.3-mm fetoscope (Miniature Straight Forward Telescope $0^{\circ} 11506$ AA; Karl Storz).

Stage I TTTS has always presented clinicians with a management dilemma. Intervention may lead to procedurerelated complications, while expectant management risks potential deterioration. Various management options have

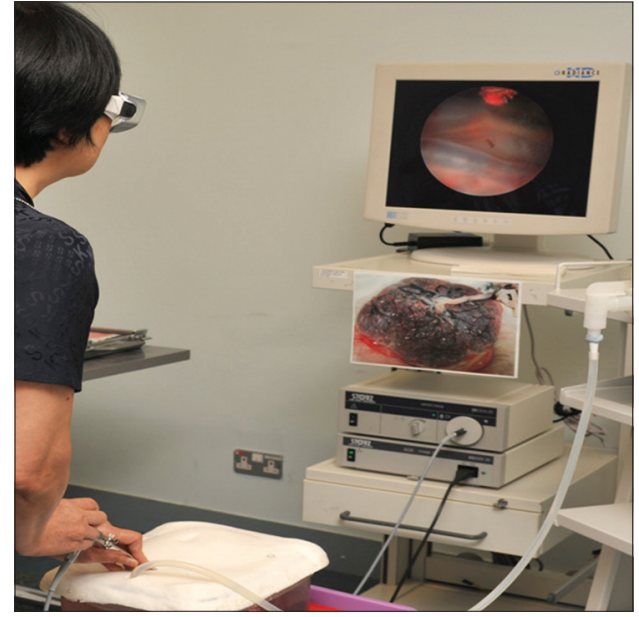

Fig. 3 Photograph shows the use of a training model at our institution to practise the skills required for fetoscopic laser photocoagulation.

been described, from expectant to amnioreduction, septostomy and laser photocoagulation of placental anastomoses. Most clinicians managed these patients conservatively, ${ }^{(33)}$ only recommending treatment if the patient lived far from hospital, was symptomatic for polyhydramnios or had a short cervix $(<1.5 \mathrm{~cm})$. O'Donoghue et $\mathrm{al}^{(34)}$ suggested that in the majority of Stage I TTTS cases, the disease remained stable $(28.3 \%)$ or regressed $(41.3 \%)$. Perinatal survival rates in those that regressed, remain stable and progressed were 90\%, 69\% and $46 \%$, respectively. Huber et al ${ }^{(35)}$ reported similar findings - only $14 \%$ of Stage I TTTS detected at 20 weeks progressed to a more severe stage requiring intervention. No difference in survival rates was reported in Stage I TTTS between cases who were treated with FLP and those who were managed conservatively. ${ }^{(36)}$ Stage I TTTS is managed expectantly in our centre, with FLP being offered to women with Stage II-III TTTS.

Our study has several limitations. The 15 cases that underwent FLP were not compared with patients who underwent other procedures that are also being used in our institution, namely amnioreduction and cord coagulation. Long-term neurological and developmental outcomes were also not assessed in our case series, as the focus was on neonatal outcomes. Due to the retrospective nature of our study, the following data was not included, unlike in prospective data collection: number of anastomosis lasered, operation time and site of port insertion.

As FLP is a highly specialised procedure for which experience in the technique translates into an increase in survival rates, ${ }^{(37,38)}$ continual training and a transparent audit system (e.g. publication of outcomes) need to be in place to point out areas for improvement. Although our centre sees a lower volume of TTTS requiring intervention compared to larger overseas institutions, we constantly strive to improve our skills and provide dedicated, comprehensive care to these high-risk pregnancies through the use of training models and various fetoscopy training workshops (Fig. 3). Several collaborations with international reputed fetal surgery centres have also allowed local doctors to learn and keep updated with the latest techniques and knowledge. 
Until recently, there were no formal training programmes for this procedure. ${ }^{(39)}$ Historically, most providers observed 5-10 procedures at an established centre before they began to offer the treatment at their own centre. In certain situations, a new physician or a trainee would join the established group and gradually transform from observing to assisting and, finally, to acting as the primary surgeon. To shorten the learning curve, Papanna et $\mathrm{al}^{(40)}$ suggested that operators could be trained by an experienced operator rather than only through observation, and progress from easier to more challenging cases. A typical new trainee might observe and assist in 15-20 cases of FLP and then perform about 20 additional cases as a primary surgeon before achieving competency. The findings by Papanna et al are important because they could be useful in establishing guidelines for training future fetoscopic interventionists and developing methods for regular audits of the performance of individual operators or centres. A performance assessment tool for FLP, developed by Peeters et al, ${ }^{(41)}$ included a validated checklist of the essential steps in FLP and also evaluated its use to ensure the competency of future fetal surgeons before they performed the procedure unsupervised, illustrating that operators may reach a level of competence after at least 25 FLP procedures. Previous studies have reported learning curves for FLP by grouping initial series and comparing it to later series. Similar to this paper, they illustrated improved outcomes in the later series. ${ }^{(37)}$ However, these studies do not describe operator-specific outcomes or the number of cases that an operator would need to reach competency to perform FLP.

In conclusion, FLP, although an effective treatment for TTTS, requires a team skilled in carrying out interventional therapies for the treatment of potential complications as well as tertiary neonatal facilities. Knowledge about the condition is also vital to ensuring timely referrals and interventions. This series shows that outcomes of FLP for TTTS in our centre were comparable to those of the international published literature and have remained stable after an initial learning curve.

\section{REFERENCES}

1. Cordero L, Franco A, Joy SD, O'shaughnessy RW. Monochorionic diamniotic infants without twin-to-twin transfusion syndrome. J Perinatol 2005; 25:753-8.

2. Berghella $\mathrm{V}$, Kaufmann M. Natural history of twin-twin transfusion syndrome. J Reprod Med 2001; 46:480-4.

3. Bajoria R, Wigglesworth J, Fisk NM. Angioarchitecture of monochorionic placentas in relation to the twin-twin transfusion syndrome. Am J Obstet Gynecol 1995; 172:856-63.

4. Denbow ML, Cox P, Taylor M, Hammal DM, Fisk NM. Placental angioarchitecture in monochorionic twin pregnancies: relationship to fetal growth, fetofetal transfusion syndrome, and pregnancy outcome. Am J Obstet Gynecol 2000; 182:417-26.

5. Ville Y, Hyett J, Hecher K, Nicolaides K. Preliminary experience with endoscopic laser surgery for severe twin-twin transfusion syndrome. N Engl J Med 1995; 332:224-7.

6. Hecher K, Plath H, Bregenzer T, Hansmann M, Hackelöer BJ. Endoscopic laser surgery versus serial amniocenteses in the treatment of severe twin-twin transfusion syndrome. Am J Obstet Gynecol 1999; 180(3 Pt 1):717-24.

7. Senat MV, Deprest J, Boulvain M, et al. Endoscopic laser surgery versus serial amnioreduction for severe twin-to-twin transfusion syndrome. N Engl J Med 2004; 351:136-44.

8. Rossi AC, D'Addario V. Laser therapy and serial amnioreduction as treatment for twin-twin transfusion syndrome: a metaanalysis and review of literature. Am J Obstet Gynecol 2008; 198:147-52.

9. Thia E, Thain S, Yeo GS. Fetoscopic laser photocoagulation in twin-to-twin transfusion syndrome: experience from a single institution. Singapore Med J 2017; 58:321-6.

10. Quintero RA, Morales WJ, Allen MH, et al. Staging of twin-twin transfusion syndrome. J Perinatol 1999; 19(8 Pt 1):550-5.

11. Slaghekke F, Lopriore E, Lewi L, et al. Fetoscopic laser coagulation of the vascular equator versus selective coagulation for twin-to-twin transfusion syndrome: an open-label randomised controlled trial. Lancet 2014; 383:2144-51.

12. Akkermans J, Peeters SH, Klumper FJ, et al. Twenty-five years of fetoscopic laser coagulation in twin-twin transfusion syndrome: a systematic review. Fetal Diagn Ther 2015; 38:241-53.

13. De Lia JE, Cruikshank DP, Keye JW Jr. Fetoscopic neodymium: YAG laser occlusion of placental vessels in severe twin-twin transfusion syndrome. Obstet Gynecol 1990; 75:1046-53.

14. Robyr R, Lewi L, Salomon LJ, et al. Prevalence and management of late fetal complications following successful selective laser coagulation of chorionic plate anastomoses in twin-to-twin transfusion syndrome. Am J Obstet Gynecol 2006; 194:796-803.

15. Lopriore E, Slaghekke F, Middeldorp JM, et al. Residual anastomoses in twinto-twin transfusion syndrome treated with selective fetoscopic laser surgery: localization, size, and consequences. Am J Obstet Gynecol 2009; 201:66.e1-4.

16. Taylor MJ, Shalev E, Tanawattanacharoen S, et al. Ultrasound-guided umbilical cord occlusion using bipolar diathermy for Stage III/IV twin-twin transfusion syndrome. Prenat Diagn 2002; 22:70-6.

17. Weisz B, Hoffmann C, Ben-Baruch S, et al. Early detection by diffusion-weighted sequence magnetic resonance imaging of severe brain lesions after fetoscopic laser coagulation for twin-twin transfusion syndrome. Ultrasound Obstet Gynecol 2014; 44:44-9.

18. Middeldorp JM, Lopriore E, Sueters M, et al. Twin-to-twin transfusion syndrome after 26 weeks of gestation: is there a role for fetoscopic laser surgery? BJOG 2007; 114:694-8.

19. Duncombe GJ, Dickinson JE, Evans SF. Perinatal characteristics and outcomes of pregnancies complicated by twin-twin transfusion syndrome. Obstet Gynecol 2003; 101:1190-6.

20. Aghajanian P, Assaf SA, Korst LM, Miller DA, Chmait RH. Fetal middle cerebral artery Doppler fluctuations after laser surgery for twin-twin transfusion syndrome. J Perinatol 2011; 31:368-72.

21. Becker J, Hernandez-Andrade E, Muñoz-Abellana B, et al. Stage-dependent fetal umbilical blood flow changes induced by laser therapy and amniodrainage in twin-to-twin transfusion syndrome. Ultrasound Obstet Gynecol 2006; 28: 674-80.

22. Zikulnig L, Hecher K, Bregenzer T, Bäz E, Hackelöer BJ. Prognostic factors in severe twin-twin transfusion syndrome treated by endoscopic laser surgery. Ultrasound Obstet Gynecol 1999; 14:380-7.

23. Gratacós E, Van Schoubroeck D, Carreras E, et al. Impact of laser coagulation in severe twin-twin transfusion syndrome on fetal Doppler indices and venous blood flow volume. Ultrasound Obstet Gynecol 2002; 20:125-30.

24. Kiserud T. In a different vein: the ductus venosus could yield much valuable information. Ultrasound Obstet Gynecol 1997; 9:369-72.

25. Beck V, Lewi P, Gucciardo L, Devlieger R. Preterm prelabor rupture of membranes and fetal survival after minimally invasive fetal surgery: a systematic review of the literature. Fetal Diagn Ther 2012; 31:1-9.

26. Papanna R, Molina S, Moise KY, Moise KJ Jr, Johnson A. Chorioamnion plugging and the risk of preterm premature rupture of membranes after laser surgery in twin-twin transfusion syndrome. Ultrasound Obstet Gynecol 2010; 35:337-43.

27. Slaghekke F, Kist WJ, Oepkes D, et al. Twin anemia-polycythemia sequence: diagnostic criteria, classification, perinatal management and outcome. Fetal Diagn Ther 2010; 27:181-90.

28. Walsh CA, McAuliffe FM. Recurrent twin-twin transfusion syndrome after selective fetoscopic laser photocoagulation: a systematic review of the literature. Ultrasound Obstet Gynecol 2012; 40:506-12.

29. van Klink JM, Koopman HM, van Zwet EW, et al. Improvement in neurodevelopmental outcome in survivors of twin-twin transfusion syndrome treated with laser surgery. Am J Obstet Gynecol 2014; 210:540.e1-7.

30. Rossi AC, Vanderbilt D, Chmait RH. Neurodevelopmental outcomes after laser therapy for twin-twin transfusion syndrome: a systematic review and metaanalysis. Obstet Gynecol 2011; 118:1145-50.

31. Salomon LJ, Ortqvist L, Aegerter P, et al. Long-term developmental follow-up of infants who participated in a randomized clinical trial of amniocentesis vs laser photocoagulation for the treatment of twin-to-twin transfusion syndrome. Am J Obstet Gynecol 2010; 203:444.e1-7.

32. Spruijt M, Steggerda S, Rath M, et al. Cerebral injury in twin-twin transfusion syndrome treated with fetoscopic laser surgery. Obstet Gynecol 2012; 120:15-20.

33. Molina S, Papanna R, Moise KJ Jr, Johnson A. Management of Stage I twin-totwin transfusion syndrome: an international survey. Ultrasound Obstet Gynecol 2010; 36:42-7.

34. O'Donoghue K, Cartwright E, Galea P, Fisk NM. Stage I twin-twin transfusion syndrome: rates of progression and regression in relation to outcome. Ultrasound Obstet Gynecol 2007; 30:958-64. 
35. Huber A, Diehl W, Zikulnig L, et al. Perinatal outcome in monochorionic twin pregnancies complicated by amniotic fluid discordance without severe twin-twin transfusion syndrome. Ultrasound Obstet Gynecol 2006; 27:48-52.

36. Wagner MM, Lopriore E, Klumper FJ, et al. Short- and long-term outcome in stage 1 twin-to-twin transfusion syndrome treated with laser surgery compared with conservative management. Am J Obstet Gynecol 2009; 201:286.e1-6.

37. Hecher K, Diehl W, Zikulnig L, Vetter M, Hackelöer BJ. Endoscopic lase coagulation of placental anastomoses in 200 pregnancies with severe midtrimester twin-to-twin transfusion syndrome. Eur J Obstet Gynecol Reprod Biol 2000; 92:135-9.

38. Morris RK, Selman TJ, Harbidge A, Martin WI, Kilby MD. Fetoscopic lase coagulation for severe twin-to-twin transfusion syndrome: factors influencing perinatal outcome, learning curve of the procedure and lessons for new centres. BJOG 2010; 117:1350-7.

39. Moise KJ Jr, Johnson A, Carpenter RJ, Baschat AA, Platt LD. Fetal intervention: providing reasonable access to quality care. Obstet Gynecol 2009; 113(2 Pt 1):408-10.

40. Papanna R, Biau DJ, Mann LK, Johnson A, Moise KJ Jr. Use of the Learning Curve-Cumulative Summation test for quantitative and individualized assessment of competency of a surgical procedure in obstetrics and gynecology: fetoscopic laser ablation as a model. Am J Obstet Gynecol 2011; 204:218.e1-9.

41. Peeters SH, Akkermans J, Bustraan J, et al. Operator competence in fetoscopic laser surgery for twin-twin transfusion syndrome: validation of a procedurespecific evaluation tool. Ultrasound Obstet Gynecol 2016; 47:350-5. 